\title{
STUDY ON THYROID FUNCTION TEST IN PREGNANCY IN A TERTIARY CARE HOSPITAL
}

\author{
Ajit Kumar Nayak $\bowtie$ \\ Department of Obstetrics \& Gynaecology ${ }^{1}$ \\ ajitnayak_og@yahoo.co.in \\ Manorama Swain \\ Department of Biochemistry ${ }^{l}$ \\ Sujata Misra \\ Department of Obstetrics \& Gynaecology ${ }^{1}$ \\ Manju Kumari Jain \\ Department of Transfusion Medicine \\ Srirama Chandra Bhanja Medical College \& Hospital \\ Mangalabag, Cuttack, Odisha, India, 753007 \\ ${ }^{1}$ Fakir Mohan Medical College \& Hospital \\ Januganj Rd, Kalidaspur, Balia, Balasore, Odisha, India, 756019
}

$\triangle$ Corresponding author

\begin{abstract}
Thyroid disorder is a very common endocrine problem encountered by pregnant women. Maternal thyroid dysfunction is associated with adverse outcome both in mother and fetus.

The aim of the study: to find out the prevalence of various thyroid disorders in pregnant women attending antenatal clinic.

Materials and methods. This prospective cross-sectional study was carried out in the Department of Obstetrics and Gynecology, F.M. Medical College \& Hospital, Balasore, Odisha from June 2020 to May 2021. 220 women with uncomplicated singleton pregnancy were included. Serum Thyroid-stimulating hormone (TSH), free T4 (FT4) and free T3 (FT3) were estimated by using electro-chemiluminescence immunoassay technique.

Results. Out of 220 pregnant women screened for thyroid dysfunction, 68 were found to have thyroid disorders. $27.3 \%$ of pregnant women had subclinical hypothyroidism, $1.4 \%$ had overt hypothyroidism, $1.8 \%$ had subclinical hyperthyroidism and $0.5 \%$ had overt hyperthyroidism. Prevalence of subclinical hypothyroidism was $6.36 \%$ when the upper reference limit of TSH level taken as $4 \mathrm{mIU} / \mathrm{L}$. Prevalence of thyroid disorder among pregnant women in the age groups 18-25 years, 26-30 years and 31-40 years were $28.9 \%, 32.1 \%$ and $38.9 \%$ respectively. There were $35.5 \%, 28 \%$ and $26 \%$ pregnant women with thyroid disorders in the first, second and third trimester respectively. Prevalence of both subclinical and overt hypothyroidism were more in multigravida compared to primigravida.

Conclusion. Our study revealed high prevalence of thyroid disorders in pregnant women and maternal subclinical hypothyroidism was the most common pattern.
\end{abstract}

Keywords: thyroid disorder, pregnancy, hypothyroidism, hyperthyroidism.

DOI: $10.21303 / 2504-5679.2021 .001918$

\section{Introduction}

Thyroid diseases are the second most common endocrine disorder affecting women in the reproductive period [1]. Thyroid hormone is necessary for fetal development and maturation. Early diagnosis and treatment of thyroid diseases before and during pregnancy is important for maintaining the health of the mother and baby. Production of thyroid hormones and iodine requirement are increased by approximately $50 \%$ during pregnancy.

At least $2 \%$ to $3 \%$ of pregnant women are affected by thyroid dysfunction. Prevalence of gestational hypothyroidism is more than gestational hyperthyroidism and it can lead to neonatal and child neurodevelopmental deficits and maternal obstetric complications.

Reports on prevalence of hypothyroidism during pregnancy from India ranges from $1.2 \%$ to $67 \%[2,3]$. Subclinical hypothyroidism, associated with increased TSH levels and normal FT4 
values is more common than overt hypothyroidism. Although subclinical hypothyroidism has been suggested to be associated with preterm labour and fetal loss, its relationship with pregnancy complications is controversial. Untreated overt hypothyroidism can result in miscarriage, preterm birth, low birth weight, still birth, placental abruption, preeclampsia, heart failure and impaired neurocognitive development [4]. Similarly, maternal overt hyperthyroidism also causes preterm birth, miscarriage, intrauterine growth restriction, low birth weight, preeclampsia, thyroid storm and heart failure. In fact, high concentrations of FT4 may be as detrimental to neurocognitive development as low FT4 [4].

In India, the most common cause of maternal hypothyroidism is iodine deficiency. Hashimoto thyroiditis is the most common cause of hypothyroidism in iodine-sufficient areas. Graves' disease, an autoimmune disease is the most common cause of maternal overt hyperthyroidism, accounts for at least $80 \%$ of these cases. Gestational transient thyrotoxicosis (GTT) estimated to occur in $1-5 \%$ of pregnancies. GTT is secondary to increased thyroid stimulation by significantly elevated human chorionic gonadotrophin.

The recent European thyroid Association guidelines concur with American Thyroid Association (ATA) and American College of Obstetricians and Gynecologists (ACOG) regarding universal screening. The optimal timing of testing is probably towards the end of the first trimester or before pregnancy in those at high risk [5]. Serum TSH estimation is the initial and most reliable test for assessing thyroid function in pregnancy [6]. Serum FT4 measurements are needed to differentiate overt hypothyroidism from subclinical hypothyroidism and for the diagnosis of euthyroid hypothyroxinaemia.

According to ATA guidelines, if laboratory dependent, trimester-specific ranges for TSH are not available, the recommended reference ranges for TSH are $0.1-2.5 \mathrm{mIU} / \mathrm{L}$ in first trimester, 0.2-3.0 mIU/L in second trimester and 0.3-3.5 mIU/L in third trimester [7]. American Endocrine Society and European Thyroid Association also quoted 0.1-2.5 mIU/L as the «normal range» for TSH in the first trimester and recommended thyroxine treatment for women with TSH $>2.5 \mathrm{mIU} / \mathrm{L}$ in the first trimester or $>3.0 \mathrm{mIU} / \mathrm{L}$ in the second and third trimester [8].

The aim of the research was to conduct the thyroid function tests in different age group of pregnant women attending antenatal clinic irrespective of number and trimesters of pregnancy and to find out prevalence of various maternal thyroid disorders.

\section{Materials and methods}

It is a hospital based cross-sectional prospective study carried out in the Department of Obstetrics and Gynaecology, F.M. Medical College \& Hospital, Balasore, Odisha, India over a period of one year from June 2020 to May 2021. Ethics Committee permission was granted for the study from Institutional Ethics Committee, F. M. Medical College \& Hospital, Balasore vide Ref. no-15/IEC Dated 24.01.2020. 220 women with uncomplicated singleton pregnancy were included in the study.

Women with personal/family history of thyroid disease or intake of thyroid drugs, smokers, multifetal gestation, known chronic disorders (diabetes and hypertension), women with certain other autoimmune disorders which are frequently associated with autoimmune thyroid dysfunction, women with prior therapeutic head or neck irradiation or patients with bad obstetrics history due to some other cause were excluded from the study. After enrolling the patients for the study, a written informed consent was taken. Detailed history, clinical examination and routine antenatal investigations were done. Blood samples were collected between 7 AM to 11 AM to avoid any variation due to circadian rhythm and sent to department of Biochemistry for thyroid hormone profile testing. Serum TSH, free T4 (FT4), free T3 (FT3) estimation were done by using electro-chemiluminescence immunoassay (e-CLIA) technique where commercially available kit (B63284-Access Reagent, 200) was used in UniCel DxI 600 Access Immunoassay System manufactured by Beckman Coulter.

Subclinical hypothyroidism was defined as increase in serum TSH level with normal FT3 and FT4. Overt hypothyroidism means increase in TSH with decrease in FT3 and FT4. Subclinical hyperthyroidism was defined as serum TSH concentration below the lower limit of reference range with FT3 and FT4 value within normal range. In overt hyperthyroidism serum TSH concentration was below the lower limit of reference range with increase in FT3 and FT4 concentration. Guidelines of the American Thyroid Association (ATA-2011) for the Diagnosis of Thyroid Disease 
during Pregnancy recommendations were adopted. Accordingly, cut-off values for serum TSH was taken as $2.5 \mathrm{mIU} / \mathrm{L}$ for first trimester, $3 \mathrm{mIU} / \mathrm{L}$ for second and third trimester and lower limit of normal serum TSH was taken as $0.04 \mathrm{mIU} / \mathrm{L}$. Collected data was processed using SPSS (Statistical Package for Social Sciences) version 21. Quantitative data were presented as mean \pm SD. Qualitative data were expressed as numbers and percentages. Results of the study finding were presented in the form of tables.

\section{Results}

Among the 220 enrolled pregnant women subjected to thyroid function test, 121 (55\%) were between the age group of 18-25 years, 81 (36.8\%) were between the age group of 26-30 years, $16(7.3 \%)$ were between the age group of $31-35$ years and $2(0.9 \%)$ were in the age group of 36-40 years. $104(47.3 \%)$ were primigravida, 67 (30.5\%) were second gravid and $49(22.2 \%)$ were gravid-3 and above. 90 (40.9\%), 107 (48.6\%) and 23 (10.5\%) were in first, second and third trimester of pregnancy respectively.

In the present study, out of 220 pregnant women screened for thyroid function, 68 women were found to have thyroid disorders with a prevalence of $30.9 \%$. 60 (27.3\%) had subclinical hypothyroidism, 3 (1.4\%) had overt hypothyroidism, 4 (1.8\%) had subclinical hyperthyroidism, $1(0.5 \%)$ had overt hyperthyroidism and 152 (69\%) were euthyroid (Table 1).

Prevalence of thyroid disorders in the first, second and third trimester was $35.5 \%, 28 \%$ and $26 \%$, respectively. Among pregnant women who had subclinical hypothyroidism $31.1 \%, 24.3 \%$ and $26 \%$ were in first, second and third trimester respectively. Among women who had overt hypothyroidism during pregnancy $2.2 \%$ and $0.9 \%$ were in first and second trimester respectively. Among maternal subclinical hyperthyroidism $1.1 \%$ and $2.8 \%$ were in first and second trimester respectively. One case $(1.1 \%)$ of maternal overt hyperthyroidism was in the first trimester of pregnancy (Table 2).

Table 1

Distribution of pregnant women according to thyroid disorders

\begin{tabular}{ccc}
\hline Thyroid Status & Number (\%) & TSH (Mean \pm SD) \\
\hline Subclinical hypothyroidism & $60(27.3 \%)$ & $3.99 \pm 1.17$ \\
Overt hypothyroidism & $3(1.4 \%)$ & $13.98 \pm 12.28$ \\
Subclinical hyperthyroidism & $4(1.8 \%)$ & $0.14 \pm 0.09$ \\
Overt Hyperthyroidism & $1(0.5 \%)$ & $0.10 \pm 0$ \\
Euthyroidism & $152(69 \%)$ & $1.61 \pm 0.69$
\end{tabular}

Table 2

Distribution of women with thyroid disorders according to trimesters

\begin{tabular}{ccccccc}
\hline \multirow{2}{*}{ Thyroid status } & \multicolumn{2}{c}{$\begin{array}{c}\text { First trimester } \\
(\boldsymbol{n}=\mathbf{9 0})\end{array}$} & $\begin{array}{c}\text { Second trimester } \\
(\boldsymbol{n}=\mathbf{1 0 7})\end{array}$ & \multicolumn{2}{c}{$\begin{array}{c}\text { Third trimester } \\
(\boldsymbol{n}=\mathbf{2 3})\end{array}$} \\
\cline { 2 - 7 } & No (\%) & $\begin{array}{c}\text { TSH } \\
(\text { Mean } \pm \text { SD) }\end{array}$ & No $(\%)$ & $\begin{array}{c}\text { TSH } \\
(\text { Mean } \pm \text { SD) }\end{array}$ & No (\%) & $\begin{array}{c}\text { TSH } \\
(\text { Mean } \pm \text { SD) }\end{array}$ \\
\hline Subclinical hypothyroidism & $28(31.1 \%)$ & $(3.94 \pm 1.38)$ & $26(24.3 \%)$ & $(4.07 \pm 1.03)$ & $6(26 \%)$ & $(3.82 \pm 0.68)$ \\
Overt hypothyroidism & $2(2.2 \%)$ & $(17.80 \pm 14.63)$ & $1(0.9 \%)$ & $(6.33 \pm 0)$ & 0 & - \\
Subclinical hyperthyroidism & $1(1.1 \%)$ & $(0.21 \pm 0)$ & $3(2.8 \%)$ & $(0.15 \pm 0.06)$ & 0 & - \\
Overt hyperthyroidism & $1(1.1 \%)$ & $(0.1 \pm 0)$ & 0 & - & 0 & - \\
Euthyroid state & $58(64.5 \%)$ & $(1.46 \pm 0.58)$ & $77(72 \%)$ & $(1.73 \pm 0.75)$ & $17(74 \%)$ & $(1.61 \pm 0.66)$
\end{tabular}

Prevalence of thyroid disorder among primigravida was $22.1 \%$ and among multigravida was $76.5 \%$. Among women who had subclinical hypothyroidism $19.2 \%$ and $68 \%$ were primi- 
gravida and multigravida respectively. All pregnant women with overt hypothyroidism were multigravida (5\%). Among maternal subclinical hyperthyroidism $1.9 \%$ and $3.5 \%$ were primigravida and multigravida respectively. One pregnant woman $(1 \%)$ had overt hyperthyroidism and was a case of primigravida (Table 3).

Prevalence of thyroid disorder among pregnant women in the age groups 18-25 years, 26-30 years and 31-40 years were $28.9 \%, 32.1 \%$ and $38.9 \%$ respectively (Table 4)

Table 3

Distribution of thyroid disorders according to number of pregnancy

\begin{tabular}{ccccccc}
\hline \multirow{2}{*}{ Thyroid disorder } & \multicolumn{2}{c}{$\begin{array}{c}\text { Primigravida } \\
(\boldsymbol{n}=\mathbf{1 0 4})\end{array}$} & \multicolumn{2}{c}{$\begin{array}{c}\text { Gravida-2 } \\
(\boldsymbol{n}=\mathbf{6 7})\end{array}$} & \multicolumn{2}{c}{$\begin{array}{c}\text { Gravida-3 \& above } \\
(\boldsymbol{n}=\mathbf{4 9})\end{array}$} \\
\cline { 2 - 7 } & No $(\%)$ & $\begin{array}{c}\text { TSH } \\
(\text { Mean } \pm \text { SD) }\end{array}$ & No $(\%)$ & $\begin{array}{c}\text { TSH } \\
(\text { Mean } \pm \text { SD) }\end{array}$ & No (\%) & $\begin{array}{c}\text { TSH } \\
\text { (Mean } \pm \text { SD) }\end{array}$ \\
\hline Subclinical hypothyroidism & $20(19.2 \%)$ & $(4.26 \pm 1.23)$ & $25(37.3 \%)$ & $(3.83 \pm 1.09)$ & $15(30.7 \%)$ & $(3.86 \pm 1.22)$ \\
Overt hypothyroidism & 0 & - & $2(3 \%)$ & $(6.89 \pm 0.79)$ & $1(2 \%)$ & $(28.15 \pm 0)$ \\
Subclinical hyperthyroidism & $2(1.9 \%)$ & $(0.16 \pm 0.08)$ & $1(1.5 \%)$ & $(0.1 \pm 0)$ & $1(2 \%)$ & $(0.14 \pm 0)$ \\
Overt hyperthyroidism & $1(1 \%)$ & $(0.1 \pm 0)$ & 0 & - & 0 & - \\
Euthyroid state & $81(77.9 \%)$ & $(1.57 \pm 0.65)$ & $39(58.2 \%)$ & $(1.70 \pm 0.63)$ & $32(65.3 \%)$ & $(1.60 \pm 0.85)$
\end{tabular}

Table 4

Distribution of thyroid disorders in pregnancy according to age groups

\begin{tabular}{ccccc}
\hline Thyroid disorder & $\mathbf{1 8 - 2 5}$ years $(\boldsymbol{n}=\mathbf{1 2 1})$ & $\mathbf{2 6}-\mathbf{3 0}$ years $(\boldsymbol{n}=\mathbf{8 1})$ & $\mathbf{3 1 - 4 0}$ years $(\boldsymbol{n}=\mathbf{1 8})$ & Mean age \pm SD \\
\hline Subclinical hypothyroidism & $31(25.6 \%)$ & $23(28.4 \%)$ & $6(33.3 \%)$ & $25.82 \pm 4.22$ \\
Overt hypothyroidism & 0 & $2(2.5 \%)$ & $1(5.6 \%)$ & $30 \pm 3.6$ \\
Subclinical hyperthyroidism & $3(2.5 \%)$ & $1(1.2 \%)$ & 0 & $23 \pm 2.94$ \\
Overt hyperthyroidism & $1(0.8 \%)$ & 0 & 0 & $19 \pm 0$ \\
Euthyroid state & $86(71 \%)$ & $55(67.9 \%)$ & $11(61.1 \%)$ & $24.9 \pm 3.59$
\end{tabular}

\section{Discussion}

As per different guidelines upper cut-off limit of TSH for defining hypothyroidism in pregnancy varied from 2.5 to $4.5 \mathrm{mIU} / \mathrm{L}$. The overall incidence of thyroid disorders in our study was $31 \%$ and $10 \%$ using 2011 ATA guidelines and 2017 ATA guidelines for thyroid function test in pregnancy respectively. Aboelroose AA reported overall incidence of thyroid disorders in low risk pregnant women was $49 \%$ and $23 \%$ as per 2011 ATA guidelines and 2017 ATA guidelines respectively [9]. Whereas, Awede B et al conducted study over 240 pregnant women and found thyroid dysfunction was present in $24.17 \%$ and $14.58 \%$ according to 2011 ATA guidelines and 2017 ATA guidelines respectively [10]. Wang $\mathrm{W}$ et al. in a multicenter cohort study among 2899 pregnant women in China, who did not use trimester specific reference ranges as recommended by ATA found prevalence of thyroid dysfunction of $10.2 \%$ [11]. The prevalence of subclinical hypothyroidism in pregnancy in our study was $27.3 \%$ when the upper reference limit of TSH value taken as $2.5 \mathrm{mlU} / \mathrm{L}$ in the first trimester and $3 \mathrm{mlU} / \mathrm{L}$ in second and third trimester. Mandal RC et al. and Panda $\mathrm{J}$ et al in their study reported its prevalence of $37.15 \%$ and $32.94 \%$ when $2.5 \mathrm{mIU} / \mathrm{L}$ taken as cut off in the TSH level $[12,13]$. Prevalence of subclinical hypothyroidism in pregnancy in the present study was $6.36 \%$ when the upper reference limit of the TSH value taken as $4 \mathrm{mIU} / \mathrm{L}$ in all trimester of pregnancy as per recent ATA (2017) guideline. Panda J et al. reported its prevalence of $3.04 \%$ when the TSH cut off is taken as $4.5 \mathrm{mIU} / \mathrm{L}$ [13]. Thanuja PM et al. observed lower prevalence of subclinical hypothyroidism in pregnancy i. e. $0.7 \%$ [14]. Whereas Singh KP et al. reported higher prevalence of maternal subclinical hypothyroidism i.e.18 \% [15].

In our study, $1.4 \%$ of pregnant women had overt hypothyroidism. Mahajan $\mathrm{K}$ et al. found $2.34 \%$ of women had maternal overt hypothyroidism in their study over 514 pregnant women [16]. 
Whereas, Dhanwal DK et al. in their study reported lower prevalence of overt hypothyroidism in pregnancy i. e. $0.7 \%$ in comparison to our study finding [17].

Hyperthyroidism is much less common than hypothyroidism. In the current study, prevalence of maternal subclinical hyperthyroidism was $1.8 \%$. Mahadik K et al. reported subclinical hyperthyroidism in $1.5 \%$ pregnant women which is almost comparable to our study finding [18]. Subclinical maternal hyperthyroidism is not associated with adverse pregnancy outcome and treatment during pregnancy is unwarranted.

In our study, the prevalence of maternal overt hyperthyroidism was $0.5 \%$. However, Cooper DS and Laurberg P in their study reported its prevalence of $0.1 \%$ [19].

In the present study, the prevalence of thyroid disorder in first, second and third trimester was $35.5 \%, 28 \%$ and $26 \%$, respectively. Dubey S et al and Rao S and Patibandla also reported higher incidence of thyroid disorder in first trimester of pregnancy compared to mid and third trimester [20, 21].

In the present study, prevalence of both subclinical and overt hypothyroidism was less in primigravida in comparison to multigravida. Subclinical and overt hyperthyroidisms were more in primigravida compared to multigravida. Whereas, Korde VR et al reported most of the primigravida patients had hypothyroidism with equal distribution of subclinical and overt disease [22].

Study limitations. As we did not estimate thyroid antibodies due to lack of facility, autoimmune cause of hypothyroidism could not be established.

Prospects for further research. As it is a study from a single tertiary care hospital representation of the sample may not be for whole of the country, so future multi-centric study is needed.

\section{Conclusions}

To conclude our study, we found higher prevalence of thyroid dysfunction, particularly subclinical hypothyroidism among pregnant women attending antenatal clinic of our hospital. Poverty, insufficient iodine supplementation and fluorinated water may be the cause of thyroid disorders. Hypothyroidism was more prevalent than hyperthyroidism. As thyroid dysfunction is associated with adverse outcome in mother and fetus, early diagnosis and intervention improves the health outcomes in pregnant women. Though various practice guidelines recommend thyroid testing only in high risk pregnant women who are symptomatic, or have a personal history of thyroid disorders, personal history of type I diabetes or other autoimmune disorders; in our country due to high prevalence of maternal thyroid disorders all pregnant women should have their thyroid function test during routine antenatal checkup especially during first trimester.

\section{Conflict of interests}

The authors declare that they have no conflicts of interest.

\section{Financing}

The study was performed without financial support.

\section{References}

[1] Negro, R., Mestman, J. H. (2011). Thyroid disease in pregnancy. Best Practice \& Research Clinical Endocrinology \& Metabolism, 25 (6), 927-943. doi: http://doi.org/10.1016/j.beem.2011.07.010

[2] Nambiar, V., Jagtap, V. S., Sarathi, V., Lila, A. R., Kamalanathan, S., Bandgar, T. R. et. al. (2011). Prevalence and Impact of Thyroid Disorders on Maternal Outcome in Asian-Indian Pregnant Women. Journal of Thyroid Research, 2011, 1-6. doi: http://doi.org/10.4061/2011/429097

[3] Rajput, R., Goel, V., Nanda, S., Rajput, M., Seth, S. (2015). Prevalence of thyroid dysfunction among women during the first trimester of pregnancy at a tertiary care hospital in Haryana. Indian Journal of Endocrinology and Metabolism, 19 (3), 416-419. doi: http://doi.org/10.4103/2230-8210.152791

[4] Practice Bulletin No. 148: Thyroid disease in pregnancy (2015). Obstetrics \& Gynecologyl, 125 (4), 996-1005. doi: http:/doi.org/ 10.1097/01.aog.0000462945.27539.93

[5] De Groot, L., Abalovich, M., Alexander, E. K., Amino, N., Barbour, L., Cobin, R. H. et. al. (2012). Management of Thyroid Dysfunction during Pregnancy and Postpartum: An Endocrine Society Clinical Practice Guideline. The Journal of Clinical Endocrinology \& Metabolism, 97 (8), 2543-2565. doi: http://doi.org/10.1210/jc.2011-2803 
[6] Glinoer, D., Spencer, C. A. (2010). Serum TSH determinations in pregnancy: how, when and why? Nature Reviews Endocrinology, 6 (9), 526-529. doi: http://doi.org/10.1038/nrendo.2010.91

[7] Stagnaro-Green, A., Abalovich, M., Alexander, E., Azizi, F., Mestman, J., Negro, R. et. al. (2011). Guidelines of the American Thyroid Association for the Diagnosis and Management of Thyroid Disease During Pregnancy and Postpartum. Thyroid, 21 (10), 1081-1125. doi: http://doi.org/10.1089/thy.2011.0087

[8] Lazarus, J., Brown, R. S., Daumerie, C., Hubalewska-Dydejczyk, A., Negro, R., Vaidya, B. (2014). 2014 European Thyroid Association Guidelines for the Management of Subclinical Hypothyroidism in Pregnancy and in Children. European Thyroid Journal, 3 (2), 76-94. doi: http://doi.org/10.1159/000362597

[9] Aboelroose, A. A. (2019). Assessment of thyroid function in pregnant women attending Suez Canal University Hospitals. International Journal of Pregnancy \& Child Birth, 5 (6), 221-224. doi: http://doi.org/10.15406/ipcb.2019.05.00181

[10] Awede, B., Hounnou, M. S., Tshabu-Aguemon, C., Adehan, G., Djrolo, F., Amoussou-Guenou, M., Laleye, A. (2018). Thyroid Function in Pregnant Women from a West-African Population. Open Journal of Molecular and Integrative Physiology, 8 (1), 1-11. doi: http://doi.org/10.4236/ojmip.2018.81001

[11] Wang, W., Teng, W., Shan, Z., Wang, S., Li, J., Zhu, L. et. al. (2011). The prevalence of thyroid disorders during early pregnancy in China: the benefits of universal screening in the first trimester of pregnancy. European Journal of Endocrinology, 164 (2), 263-268. doi: http://doi.org/10.1530/eje-10-0660

[12] Das, A., Mandal, R., Bhar, D., Basunia, S., Kundu, S., Mahapatra, C. (2016). Subclinical hypothyroidism in pregnancy: An emerging problem in Southern West Bengal: A cross-sectional study. Journal of Natural Science, Biology and Medicine, 7 (1), 80-84. doi: http://doi.org/10.4103/0976-9668.175080

[13] Panda J, Maji A, Mishra J, Manjareeka M. (2018). Thyroid Disorders in Pregnancy: An Exploratory Study. Journal of Clinical and Diagnostic Research, 12 (3). doi: http://doi.org/10.7860/jcdr/2018/34837.11288

[14] Thanuja, P. M., Rajgopal, K., Sadiqunnisa (2014). Thyroid Dysfunction In Pregnancy And Its Maternal Outcome. IOSR Journal of Dental and Medical Sciences, 13 (1), 11-15. doi: http://doi.org/10.9790/0853-131101115

[15] Singh, K. P., Singh, H. A., Kamei, H., Devi, L. M. (2015). Prevalence of hypothyroidism among pregnant women in the sub mountain state of Manipur. International Journal of Scientific Study, 5 (5), 143-146.

[16] Mahajan, K., Mahajan, S. (2020). Fetal outcome in pregnancy with thyroid dysfunction: Observational study. Pravara Medical Review, 12 (3), 37-42.

[17] Dhanwal, D., Prasad, S., Agarwal, A., Dixit, V., Banerjee, A. (2013). High prevalence of subclinical hypothyroidism during first trimester of pregnancy in North India. Indian Journal of Endocrinology and Metabolism, 17 (2), $281-284$. doi: http://doi.org/10.4103/2230-8210.109712

[18] Mahadik, K., Choudhary, P., Roy, P. K. (2020). Study of thyroid function in pregnancy, its feto-maternal outcome; a prospective observational study. BMC Pregnancy and Childbirth, 20 (1). doi: http://doi.org/10.1186/s12884-020-03448-Z

[19] Cooper, D. S., Laurberg, P. (2013). Hyperthyroidism in pregnancy. The Lancet Diabetes \& Endocrinology, 1 (3), $238-249$. doi: http://doi.org/10.1016/s2213-8587(13)70086-x

[20] Dubey, S., Pradhan, A. (2017). Thyroid disorder in antenatal women in sub-himalayan region: a need for universal screening. International Journal of Reproduction, Contraception, Obstetrics and Gynecology, 6 (8), 3445-3448. doi: http://doi.org/ 10.18203/2320-1770.ijrcog20173460

[21] Rao, S., Patibandla, A. (2016). A Study to find out the Prevalence of Hypothyroidism among Pregnant Women Visiting ESI Hospital Sanathnagar Hyderabad. Gynecology \& Obstetrics, 6 (3). doi: http://doi.org/10.4172/2161-0932.1000363

[22] Korde, V. R., Barse, S. P., Barla, J. S. (2018). Prevalence of thyroid dysfunctions in pregnant women: a prospective study in a tertiary care hospital in Maharashtra, India. International Journal of Reproduction, Contraception, Obstetrics and Gynecology, 7 (8), 3211-3215. doi: http://doi.org/10.18203/2320-1770.ijrcog20183319

Received date 21.06.2021

(C) The Author(s) 2021

Accepted date 20.07.2021

This is an open access article

Published date 30.07.2021

under the Creative Commons CC BY license

How to cite: Nayak, A. K., Swain, M., Misra, S., Jain, M. K. (2021). Study on thyroid function test in pregnancy in a tertiary care hospital. EUREKA: Health Sciences, 4, 20-25. doi: http://doi.org/10.21303/2504-5679.2021.001918 